\title{
Research on Influencing Factors of Technological Independent Innovation of Equipment Manufacturing Enterprises from the Perspective of Iceberg Theory
}

\author{
Tie Liu, Xu Yang, and Yu Guo \\ School of Economics and Management, Harbin Engineering University, Harbin, China \\ Correspondence should be addressed to Yu Guo; gyu1991@hrbeu.edu.cn
}

Received 30 August 2021; Revised 12 September 2021; Accepted 27 September 2021; Published 12 October 2021

Academic Editor: Wei Zhang

Copyright ( 2021 Tie Liu et al. This is an open access article distributed under the Creative Commons Attribution License, which permits unrestricted use, distribution, and reproduction in any medium, provided the original work is properly cited.

\begin{abstract}
Technological independent innovation is not only the internal need for equipment manufacturing enterprises to improve their core competitiveness but also the urgent requirement to promote economic and social development. Based on the development status of technological independent innovation of equipment manufacturing enterprises, this study analyzes the explicit and implicit influencing factors of technological independent innovation using iceberg theory and obtains the multilevel hierarchical structure model of explicit and implicit influencing factors and its key influencing factors using the integrated DEMATEL-ISM method. The three aspects of enterprises give suggestions and countermeasures for the existing problems, put forward correct and effective guidance for the technological independent innovation of equipment manufacturing enterprises, and lay a solid foundation for China's industrial revitalization and economic development.
\end{abstract}

\section{Introduction}

Innovation is not only the inexhaustible source of national development but also the foundation of China's modern economic system construction. The equipment manufacturing industry has always been an important force for the sustainable development of China's industrial economy. At this stage, the equipment manufacturing industry has accelerated its development to digitization, intelligence, and service, and a series of new models, such as sharing economy and digital economy, have emerged, which has brought opportunities for the technological independent innovation of China's equipment manufacturing enterprises. On the other hand, the development of China's heavy chemical industry and export-oriented industry is facing an inflection point. Therefore, exploring the dominant and recessive key influencing factors of technological independent innovation of equipment manufacturing enterprises can provide reference and guidance for the in-depth development of relevant theories of technological independent innovation of equipment manufacturing enterprises to a certain extent. At the same time, it can help equipment manufacturing enterprises determine the influencing factors of technological independent innovation and put forward scientific and effective countermeasures and suggestions. Breaking the situation of independent technological innovation in passive innovation based on market demand has important practical and strategic significance.

Scholars at home and abroad have explored independent technological innovation. In terms of the connotation of independent technological innovation, Fransman and King [1] pointed out that independent technological innovation can be obtained from the development history of improving the technological level of enterprises in developing countries. Raghu and Praveen [2] believed that technological independent innovation can be realized through the accumulation, storage, maintenance, and activation of knowledge by enterprises. Wu et al. [3] believed that independent innovation is an endogenous innovation, which is a process of using the organization's own intellectual assets and capabilities to develop new products and services and obtain its own intellectual property rights and core technologies. 
Wang et al. [4] believed that independent innovation capability refers to the ability of enterprises to rely on their own strength to transform innovative resources, such as knowledge into new products, new processes, new services, and new brands, so as to explore new markets. Zhou et al. [5] believed that the independent innovation ability of enterprises is not only reflected in technological output but also in economic benefits. In the research on the influencing factors of enterprise technology independent innovation, innovation environment [6], innovation output [7], foreign capital introduction [8], and other factors significantly affect the technology independent innovation of equipment manufacturing industry. Zhu and Lei [9] believed that it is necessary to evaluate enterprise independent innovation from four dimensions: innovation input capacity, $R \& D$ capacity, innovation output capacity, and innovation potential. Wu et al. [3] believed that the realization of independent innovation in equipment manufacturing industry needs to pay attention to technical capability and technical management. Technical capability is the process of acquiring technical knowledge or organizational learning. Technical management includes a number of management systems, such as technical strategy, organizational structure, and corporate culture. Wang et al. [4] believed that the realization of independent innovation in petroleum equipment manufacturing industry requires knowledge integration ability, including knowledge identification ability, knowledge transformation ability, knowledge integration ability, and knowledge application ability. Hervasoliver et al. [10] found that process innovation, organizational innovation, and product innovation can significantly improve the technological independent innovation ability of high-end equipment manufacturing enterprises. Zhou et al. [5] divided the independent innovation performance of Listed Companies in strategic emerging industries into three aspects: government intervention, innovation investment, and financial expenditure. At the same time, the research methods related to technological independent innovation can be summarized into three categories: the first category is evaluation research. Zhang et al. [11] proposed a comprehensive evaluation model based on evidence reasoning, and they evaluated and analyzed the independent innovation ability of automobile industry in Anhui Province Based on D-S evidence theory. Zhu and Lei [9] used the fuzzy comprehensive evaluation method to evaluate the independent innovation ability. Si and Qiao [12] analyzed the dynamic development trend of independent technological innovation efficiency of equipment manufacturing industry and its subindustries from 2010 to 2014 using CCR model, BCC model, and scale efficiency method in DEA. Lin et al. [13] used the innovation input and output data of 12 listed tourism equipment manufacturing companies from 2011 to 2017 and analyzed the efficiency of technological independent innovation using DEA Malmquist method. The second category is case study. Wu et al. [3] verified the double helix independent innovation model based on technical capability and technology management through case analysis. The third category is regression research. Zhou et al. [5] uses GMM panel estimation method to measure the impact of government intervention on independent innovation performance based on the data of Listed Companies in China's strategic emerging industries and analyzes the impact of financial support on the effect of government intervention.

To sum up, the relevant research on the influencing factors of technological independent innovation of equipment manufacturing enterprises is relatively rich, but most studies do not analyze the influencing factors comprehensively and systematically and lack theoretical support and reasonable framework when analyzing the influencing factors, resulting in insufficient in-depth analysis and single use of research methods, which affects the theoretical and practical significance of the research results. Based on the development status of technological independent innovation of equipment manufacturing enterprises, this study uses the iceberg theory to clarify the explicit and implicit influencing factors of technological independent innovation of equipment manufacturing enterprises, obtains the multilevel hierarchical structure model of explicit and implicit influencing factors using the integrated DEMATEL-ISM method, and identifies the explicit and implicit key influencing factors, From the perspective of the main body of technological independent innovation, this study puts forward countermeasures and suggestions to realize the technological independent innovation of equipment manufacturing enterprises, which can improve the technological independent innovation ability of equipment manufacturing enterprises and lay a solid foundation for the revitalization and upgrading of equipment manufacturing industry and economic development.

\section{Theoretical Basis}

2.1. Iceberg Theoretical Model. In 1985, Austrian psychologist Freud first put forward the famous "Iceberg Theory." Then, he combined with the theory of spiritual hierarchy and analyzed how people's psychology affects their behavior. The core idea of "Iceberg Theory" is to compare human personality to an iceberg on the sea, consciousness is the part above sea level, and the subconscious is the part below sea level. Sea level is the preconsciousness between the two. It means that human activities are influenced by explicit and implicit levels [14].

Subconsciousness refers to the consciousness deeply hidden in people's hearts, disturbed, and repressed by other emotions and not displayed. It is the most hidden, fundamental, and primitive psychological feature in the bottom of human heart and will drive all human external behaviors. It is difficult for self to detect [15]. Therefore, considering that the society may not recognize some psychological behaviors generated by the subconscious, which leads to the repression of the subconscious to a certain extent, but it will not cause the disappearance of the subconscious. Instead, it will be required to get all kinds of satisfaction, prompting people to produce some external behaviors to get satisfaction. Consciousness refers to being on the surface of people's psychology, self-aware, and able to express their feelings about the real world through language and other ways. Preconsciousness is an intermediate consciousness connecting the 
subconscious and consciousness, which mainly plays a regulatory role. It can convert the subconscious into consciousness. However, in most cases, due to the barbaric characteristics of the subconscious, the role of preconsciousness is usually to prevent the subconscious from converting into consciousness [16]. According to the description of subconsciousness, preconsciousness, and consciousness, the core idea of "Iceberg Theory" is to compare human personality to an iceberg on the sea, consciousness is the part above sea level, and the subconscious is the part below sea level. Sea level is the pre consciousness between the two. For an iceberg, as long as the part below sea level is fragmented, the iceberg will no longer exist. Therefore, most of the influence on human behavior is subconscious, and the influence of consciousness on human behavior is obviously weaker than that of subconscious. In other words, human activities are affected by two levels, namely, the explicit level and the implicit level. Among the two, the invisible hidden level plays a key role, which determines people's behavior. As shown in Figure 1 above.

2.2. Advantages of Iceberg Theory Perspective. Iceberg theory is divided into above and below the ice, which is actually a metaphor. The development process of an enterprise is similar to the growth process of people. Therefore, the enterprise is regarded as an organization with life characteristics. When studying the law of its survival and development, the study can also use the idea of iceberg theory. Hines [17] studied the purchasing decision of local fashion sales industry and put forward and discussed the cost comparison iceberg theory. Guan and Liang [18] constructed the profitability evaluation model of high-tech enterprises and pointed out the problems existing in their profitability. Abbasi [19] used the iceberg theory to explore the explicit and implicit culture in the insurance system culture and pointed out that the implicit part is the root cause of action. Gui and $\mathrm{Na}$ [20] analyzed the influencing factors of production logistics operation of manufacturing enterprises using iceberg theory. Grigg et al. [21] summarized and analyzed the factors affecting the profitability of small- and medium-sized enterprises using the iceberg theory. Chen et al. [22] analyzed the ability and quality of professionals in building environment and energy engineering based on iceberg theory. Based on iceberg theory, Cao and Dong [23] did research on human resource management model of forestry science and technology enterprises in the era of big data.

To sum up, the advantages of iceberg theory perspective are as follows: first, iceberg theory perspective has a more global view. Iceberg theory emphasizes the integrity of things. Above and below the ice just form a complete whole. Second, iceberg theory is more essential. "Iceberg" can better "dissect" the essence of the problem. The problem studied is like a huge iceberg. What the outside world can see is only a corner of the surface (dominant), about $1 / 8$ of which is displayed above the water surface, whereas $7 / 8$ of the huge "mountain" is below the invisible ice surface (recessive), which needs to be excavated, analyzed, and applied.

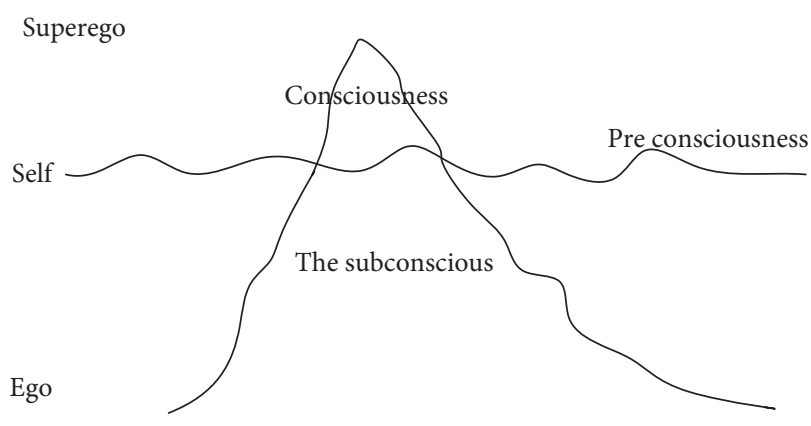

FIgURE 1: Iceberg theoretical model.

\section{Determination of Influencing Factors of Technology Independent Innovation of Equipment Manufacturing Enterprises under Iceberg Theory}

In this study, the Iceberg Theory is introduced into the research of the technology independent innovation of the equipment manufacturing enterprises; it excavates and identifies the deep factors hidden behind the technological independent innovation of equipment manufacturing enterprises, can systematically and comprehensively analyze the influencing factors of technological independent innovation of equipment manufacturing enterprises, and clarify the characteristics and effects of their dominant and recessive influencing factors. It provides more measures to improve the ability of independent technological innovation. The part above sea level is mainly reflected in the realization of the technology independent innovation of the equipment manufacturing enterprises, which is the dominant influencing factor, and the main role is the equipment manufacturing enterprises. The part below the sea level is mainly reflected in the willingness of all parties to support the realization of the technology independent innovation of the equipment manufacturing enterprises, and it is its hidden influencing factor. The main bodies of the role are the government and universities (scientific research institutions). Both explicit and implicit influencing factors constitute the influencing factors of the technology independent innovation of the equipment manufacturing enterprises.

3.1. Alternative Influencing Factors. At the present stage, in order to ensure the development of equipment manufacturing industry, the government reflects new competitive advantages in high-end manufacturing, core technology, core components, and other aspects, and it provides a good policy environment support for equipment manufacturing enterprises' technological independent innovation by means of tax reduction, capital subsidies, risk investment, policy support, and other means. Many colleges and universities, research institutes, such as research and development, strengthen the construction of a combination of science and technology innovation system 1) to promote industrial projects, 2) to provide the equipment manufacturing industry enterprise innovative talents, knowledge, and technology innovation, 3) to make them get 
more diverse external resources, and 4) to enhance the equipment manufacturing industry enterprise's technology innovation base. Equipment manufacturing enterprises continue to increase investment in technological innovation and accelerate the transformation of technological innovation achievements. In recent years, from the perspective of technology market income and total assets, the technological innovation level of equipment manufacturing enterprises has been continuously improved, and the technological income has continued to grow. At the same time, domestic and foreign scholars have done a lot of research on the influencing factors of technology independent innovation of equipment manufacturing enterprises. According to the connotation of explicit and implicit influencing factors of technology independent innovation of equipment manufacturing enterprises from the perspective of Iceberg Theory, the explicit and implicit influencing factors of technology independent innovation of equipment manufacturing enterprises are obtained.

\subsubsection{Dominant Influencing Factors}

(1) Innovation Strength. Enterprises with strong innovation strength often have a more perfect innovation foundation. Strong innovation strength helps their R\&D personnel to improve their R\&D efficiency, strengthen communication and cooperation between teams and departments, and provide more funds, and personnel and resource support for enterprises' independent technological innovation [24]. According to the research of Stefano et al. [25] and $\mathrm{Yu}$ and Lei [26], innovation strength can be measured by the following indicators: The scale of the enterprise, the nature of the property right of the enterprise, the adaptability of the organizational structure of the enterprise, the reasonableness of the strategic goal and development plan of the enterprise in five years, the construction status of the enterprise culture, the quality of the enterprise management team, the financial status of the enterprise in five years, and the acuity of the entrepreneur's independent technological innovation and risk consciousness.

(2) Innovation Ability. The stronger the innovation ability of an enterprise, the higher the consciousness and ability of independent innovation, the higher the quality of production and technical personnel, the stronger the innovation ability is conducive to shorten the new product research and development cycle, strengthen the internal and external information exchange and communication of the enterprise, and improve the transformation rate of scientific and technological achievements. According to the research of Wang et al. [27], Soto et al. [28], and Lin and Wang [29], innovation capability can be measured by the following indicators: research and development and production process collaboration capabilities, new product development cycle, research results to production rate, the strength of technical transformation, the degree of cooperation with universities, research institutes, professional research and development personnel, enterprise scale, enterprise production plan completion rate measurement in the manufacture, test and standardization level of situation, enterprise system and the core team stability, invention patents, and technology innovation success rate.

(3) Innovative Products. Level of enterprise innovation and product innovation, market share, degree of product differentiation, and other factors not only determines the implementation of enterprise technology innovation effect but also reflects the enterprise technology innovation ability and level, so as to develop high-quality innovative products with market competitiveness, directly affect the enterprise technology innovation to achieve [30]. Zhang et al. [11], Zhao and Zhu [31], and He [32] all point out that innovative products can be measured by the following indicators: product technical innovation level, product differentiation level, product yield rate, product market share, product market positioning accuracy, and product function and quality level.

(4) Innovation Participation. It fully reflects the user through the involvement of the innovative products in terms of appearance, function, turnover rate, and satisfaction with the degree of the user's trust in the enterprise, innovation, and participation. It not only provide the enterprise technology innovation output of intuitive reflect market satisfaction, innovation, and participation, but also will guide enterprises to adjust and perfect the direction and content of technology innovation, etc. According to the literature of $\mathrm{He}$ et al. [32], Berglund and Hellstrom [33], and Hellström and Hellström [34], innovation participation can be measured by the following indicators: degree of user demand for products, customer satisfaction for product in line with expectations, user satisfaction of product, the user's trust in the products, the speed of changes in customer demand for products, users of product acquisition, user satisfaction with the degree of satisfaction for product update speed, and the user's satisfaction with the personalized design of product.

\subsubsection{Hidden Influencing Factors}

(1) Innovation Input. Technology independent innovation investment of enterprises includes human capital investment, and capital and equipment investment. Scientific and technological talents and research and development personnel are the core figures in the realization of independent technological innovation in equipment manufacturing enterprises, but it is often not enough to only invest in personnel, capital and equipment, and other inputs, such as market development cost input, and non-RESEARCH and development input is also needed. According to the research results of Knight [35], Du [36], and Zhang et al. [37], innovation input can be measured by the following indicators: Technology R\&D investment level, R\&D investment growth rate, investment intensity of epitaxial innovation resources, investment intensity of market development costs, investment intensity of related equipment, investment level of fulltime technical personnel, training intensity of technical 
personnel, construction level of information platform, and the intensity of advanced technological achievements.

(2) Innovation Environment. Innovation environment is the "base" for equipment manufacturing enterprises to carry out innovation activities. The more solid the innovation guarantee provided by a good environment for enterprises, the more sufficient the resources and guarantee obtained by enterprises from the innovation environment, and the more conducive to the development of independent technological innovation activities. Xu [38], Lin and Wang [29], and Zhang et al. [39] believed that innovation input can be measured by the following indicators: market structure, market competition, market demand, the government technical aid strength, the strength of technology development finance capital support, infrastructure construction scale, the industry-university-institute cooperation platform scale, market concentration degree, enterprise area natural condition, geographical location, climatic conditions, trend of independent technological innovation in the industry as a whole, and coverage scale of technological innovation network. The extent to which the district effectively protects the property rights of enterprises' independent innovation achievements and the extent to which the region where the enterprise is located promote enterprises' independent technological innovation.

3.2. Important Influencing Factors. Considering the complexity of calculation and the typical characteristics of indicators, using the Delphi expert survey method to identify important influencing factors of independent technological innovation of equipment manufacturing enterprises from the perspectives of explicit and implicit influencing factors, the main steps are as follows:

(1) In the form of a set, the $n$ candidate factors are expressed as $f=\left(f_{1}, f_{2}, \ldots, f_{n}\right)^{T}$ :

(2) Determine the degree of importance of alternative factors to the realization of independent technological innovation of equipment manufacturing enterprises. According to the content of the questionnaire, the rating is divided into five levels, which are recorded as follows:

$X=\left\{X_{1}, X_{2}, X_{3}, X_{4}, X_{5}\right\}=\{$ very important, more important, generally, less important, very unimportant $\}=\{0.9,0.7,0.5,0.3,0.1\}$

Using a questionnaire survey, 12 experts and managers of equipment manufacturing companies evaluated the importance of all alternative influencing factors, including 7 managers from related companies and 5 experts from university. All respondents are older than 30 years, 7 managers have more than 5 years of experience in equipment manufacturing companies, and 5 experts from university are doctoral tutors with research directions in technological innovation and business management. All the questionnaires were contacted with the respondents before they were distributed, and they were distributed by e-mail. After the questionnaires were collected, the evaluation results of the 12 respondents were sorted out and summarized.

(3) Determine the importance evaluation matrix of the alternative influencing factors. According to the respondent's evaluation results of the $n$-th alternative influencing factors, the total evaluation matrix is calculated, and the evaluation factor is denoted as $a_{i j}=d_{i j} / 12$, where $d_{i j}$ represents the number of the $i$-th respondent who chose the $j$-th evaluation value. The total evaluation matrix can be recorded as follows:

$$
A=\left[\begin{array}{c}
A_{1} \\
A_{2} \\
\vdots \\
A_{3}
\end{array}\right]=\left[\begin{array}{cccc}
a_{11} & a_{12} & \cdots & a_{1 j} \\
a_{21} & a_{22} & \cdots & a_{2 j} \\
\vdots & \vdots & \ddots & \vdots \\
a_{i 1} & a_{i 2} & \cdots & a_{i j}
\end{array}\right] .
$$

(4) Calculate the importance evaluation value of alternative influencing factors. Use formula $Y=A X^{T}$ to get the importance evaluation value of each alternative factor.

(5) Identify important influencing factors. Record the importance evaluation value $y_{i}>0.6$ as an important influencing factor.

Comprehensively considering the complexity of calculation and the typical characteristics of indicators, the Delphi expert survey method is used to identify the explicit and implicit important influencing factors of independent technological innovation of equipment manufacturing enterprises. Table 1 summarizes managers and experts' evaluation of the importance of explicit and implicit alternative influencing factors. Record the value of $y_{i}>0.6$ as the explicit and implicit alternative influencing factors as important influencing factors, so as to screen out 15 explicit important influencing factors (denoted as $D_{1}-D_{15}$ ) and 12 implicit important influencing factors (denoted as $\left.R_{1}-R_{12}\right)$.

\section{Hierarchical Structure Analysis of Influencing Factors of Technology Independent Innovation in Equipment Manufacturing Enterprises under "Iceberg Theory"}

4.1. Research Methods. OIn recent years, a variety of method combinations have been widely used [40]. The integrated DEMATEL-ISM method is based on the commonness of DEMATEL model and ISM model. Its advantage is that it can simplify the calculation of reachability matrix and is widely used in various studies, such as communication network system structure analysis [41], public management field [42], and transportation module research [43]. 
TABLE 1: Evaluation value of alternative influencing factors of technological independent innovation in equipment manufacturing enterprises.

\begin{tabular}{|c|c|c|c|c|}
\hline $\begin{array}{l}\text { First-level influencing } \\
\text { factors }\end{array}$ & $\begin{array}{l}\text { Second-level } \\
\text { influencing } \\
\text { factors }\end{array}$ & Third-level influencing factors & $\begin{array}{c}\text { Importance } \\
\text { evaluation value } \\
y_{i}\end{array}$ & $\begin{array}{c}\text { Important } \\
\text { influencing factor } \\
\text { level }\end{array}$ \\
\hline \multirow{32}{*}{$\begin{array}{l}\text { Explicit influence factor } \\
\text { (enterprise) }\end{array}$} & \multirow{8}{*}{$\begin{array}{l}\text { Innovation } \\
\text { strength }\end{array}$} & Enterprise scale & 0.677 & $D_{1}$ \\
\hline & & The nature of enterprise property rights & 0.550 & - \\
\hline & & Enterprise organizational structure adaptability & 0.373 & - \\
\hline & & $\begin{array}{l}\text { The enterprise 5-year strategic goal and the } \\
\text { rationality of its development plan }\end{array}$ & 0.483 & - \\
\hline & & Enterprise culture construction status & 0.843 & $D_{2}$ \\
\hline & & Enterprise management team quality & 0.676 & $D_{3}$ \\
\hline & & Five-year financial status of the enterprise & 0.683 & $D_{4}$ \\
\hline & & $\begin{array}{l}\text { The acuity and risk awareness of entrepreneurs' } \\
\text { technological independent innovation }\end{array}$ & 0.830 & $D_{5}$ \\
\hline & \multirow{11}{*}{ Innovation ability } & $\begin{array}{c}\mathrm{R} \& \mathrm{D} \text { and production process collaboration } \\
\text { ability }\end{array}$ & 0.403 & - \\
\hline & & New product $R \& D$ period & 0.538 & - \\
\hline & & Production rate of research results & 0.737 & $D_{6}$ \\
\hline & & Intensity of technological transformation & 0.574 & - \\
\hline & & $\begin{array}{c}\text { Degree of cooperation with universities and } \\
\text { research institutes }\end{array}$ & 0.912 & $D_{7}$ \\
\hline & & Proportion of professional R\&D personnel & 0.873 & $D_{8}$ \\
\hline & & Enterprise production plan completion rate & 0.507 & - \\
\hline & & $\begin{array}{l}\text { Enterprise's measurement, testing, and } \\
\text { standardization level status in manufacturing }\end{array}$ & 0.557 & - \\
\hline & & Enterprise system and core team stability & 0.470 & - \\
\hline & & Number of enterprise invention patents & 0.509 & - \\
\hline & & Technological innovation success rate & 0.635 & $D_{9}$ \\
\hline & \multirow{6}{*}{$\begin{array}{l}\text { Innovation } \\
\text { product }\end{array}$} & Product technology innovation level & 0.724 & $D_{10}$ \\
\hline & & Degree of product differentiation & 0.493 & - \\
\hline & & Product output rate & 0.760 & $D_{11}$ \\
\hline & & Product market share & 0.636 & $D_{12}$ \\
\hline & & Product market positioning accuracy & 0.504 & - \\
\hline & & Product function and quality level & 0.597 & - \\
\hline & \multirow{7}{*}{$\begin{array}{l}\text { Innovation } \\
\text { participation }\end{array}$} & The degree of user demand for the product & 0.653 & $D_{13}$ \\
\hline & & $\begin{array}{l}\text { The degree of user satisfaction that the product } \\
\text { meets expectations }\end{array}$ & 0.453 & - \\
\hline & & User satisfaction with the product & 0.807 & $D_{14}$ \\
\hline & & The degree of user trust in the product & 0.658 & $D_{15}$ \\
\hline & & $\begin{array}{c}\text { The speed of changes in user demand for } \\
\text { products }\end{array}$ & 0.504 & - \\
\hline & & User satisfaction with product update speed & 0.533 & - \\
\hline & & $\begin{array}{c}\text { User satisfaction with product personalized } \\
\text { design }\end{array}$ & 0.383 & - \\
\hline
\end{tabular}


TABle 1: Continued.

\begin{tabular}{|c|c|c|c|c|}
\hline $\begin{array}{l}\text { First-level influencing } \\
\text { factors }\end{array}$ & $\begin{array}{l}\text { Second-level } \\
\text { influencing } \\
\text { factors }\end{array}$ & Third-level influencing factors & $\begin{array}{c}\text { Importance } \\
\text { evaluation value } \\
y_{i}\end{array}$ & $\begin{array}{l}\text { Important } \\
\text { influencing factor } \\
\text { level }\end{array}$ \\
\hline \multirow{23}{*}{$\begin{array}{l}\text { Implicit influence factor } \\
\text { (government, colleges } \\
\text { (research institutions)) }\end{array}$} & \multirow{9}{*}{$\begin{array}{l}\text { Innovation } \\
\text { investment }\end{array}$} & Technology R\&D investment level & 0.775 & $R_{1}$ \\
\hline & & Growth rate of R\&D investment & 0.735 & $R_{2}$ \\
\hline & & Investment in extension innovation resources & 0.523 & - \\
\hline & & Investment in market development & 0.407 & - \\
\hline & & Related equipment investment intensity & 0.472 & - \\
\hline & & Investment level of full-time technicians & 0.539 & - \\
\hline & & Training intensity of technicians & 0.540 & - \\
\hline & & Information platform construction level & 0.523 & - \\
\hline & & $\begin{array}{c}\text { Introduction of advanced technological } \\
\text { achievements }\end{array}$ & 0.874 & $R_{3}$ \\
\hline & \multirow{14}{*}{$\begin{array}{l}\text { Innovation } \\
\text { environment }\end{array}$} & Market structure & 0.653 & $R_{4}$ \\
\hline & & Market competition scale & 0.638 & $R_{5}$ \\
\hline & & Market demand & 0.717 & $R_{6}$ \\
\hline & & Intensity of government technical subsidies & 0.824 & $R_{7}$ \\
\hline & & Infrastructure construction scale & 0.680 & $R_{8}$ \\
\hline & & $\begin{array}{c}\text { Financial support intensity of technology } \\
\text { development }\end{array}$ & 0.703 & $R_{9}$ \\
\hline & & User satisfaction with product acquisition & 0.689 & $R_{10}$ \\
\hline & & $\begin{array}{l}\text { Scale of industry university research cooperation } \\
\text { platform }\end{array}$ & 0.814 & $R_{11}$ \\
\hline & & Market concentration & 0.504 & - \\
\hline & & $\begin{array}{l}\text { Degree of promoting independent technological } \\
\text { innovation in the region where the enterprise is } \\
\text { located }\end{array}$ & 0.794 & $R_{12}$ \\
\hline & & $\begin{array}{l}\text { Trend of independent technological innovation } \\
\text { in the industry as a whole }\end{array}$ & 0.590 & - \\
\hline & & $\begin{array}{c}\text { Coverage scale of technological innovation } \\
\text { network }\end{array}$ & 0.407 & - \\
\hline & & $\begin{array}{l}\text { Degree of effective protection of property rights } \\
\text { of independent innovation achievements in the } \\
\text { region where the enterprise is located }\end{array}$ & 0.508 & - \\
\hline & & $\begin{array}{l}\text { Natural conditions of the area where the } \\
\text { enterprise is located (geographical location and } \\
\text { climatic conditions) }\end{array}$ & 0.539 & - \\
\hline
\end{tabular}

DEMATEL method can accurately obtain the primary and secondary influencing factors in the influencing process and the degree of influence between them. ISM model can hierarchy and structure complex influencing factors and finally establish a multilevel hierarchical structure model to clearly express the relationship between influencing factors. This study adopts the integrated DEMATEL-ISM method, which is divided into two stages. In the first stage, the influencing factors affecting enterprise quality defects are analyzed using the DEMATEL method. After the comprehensive influence matrix is obtained using the DEMATEL method, plus the unit matrix of the same order, the comprehensive influence matrix is obtained after transformation, and the threshold is set reasonably $\lambda$, the standardized reachability matrix is obtained; In the second stage, the ISM model is used to build a multilevel hierarchical structure model. The specific construction ideas are shown in Figure 2.

\subsection{Hierarchy of Influencing Factors}

\subsubsection{Dominant Influencing Factors}

(1) Establish the Direct Influence Matrix. The influencing factors shown in Table 1 play a direct or indirect role in the technological independent innovation of equipment manufacturing enterprises, and each influencing factor also influences and interacts with each other. $D_{i}$ is the equipment manufacturing enterprise technology independent innovation influencing factors, using Delphi Method to get the direct impact matrix $W_{d}$. 


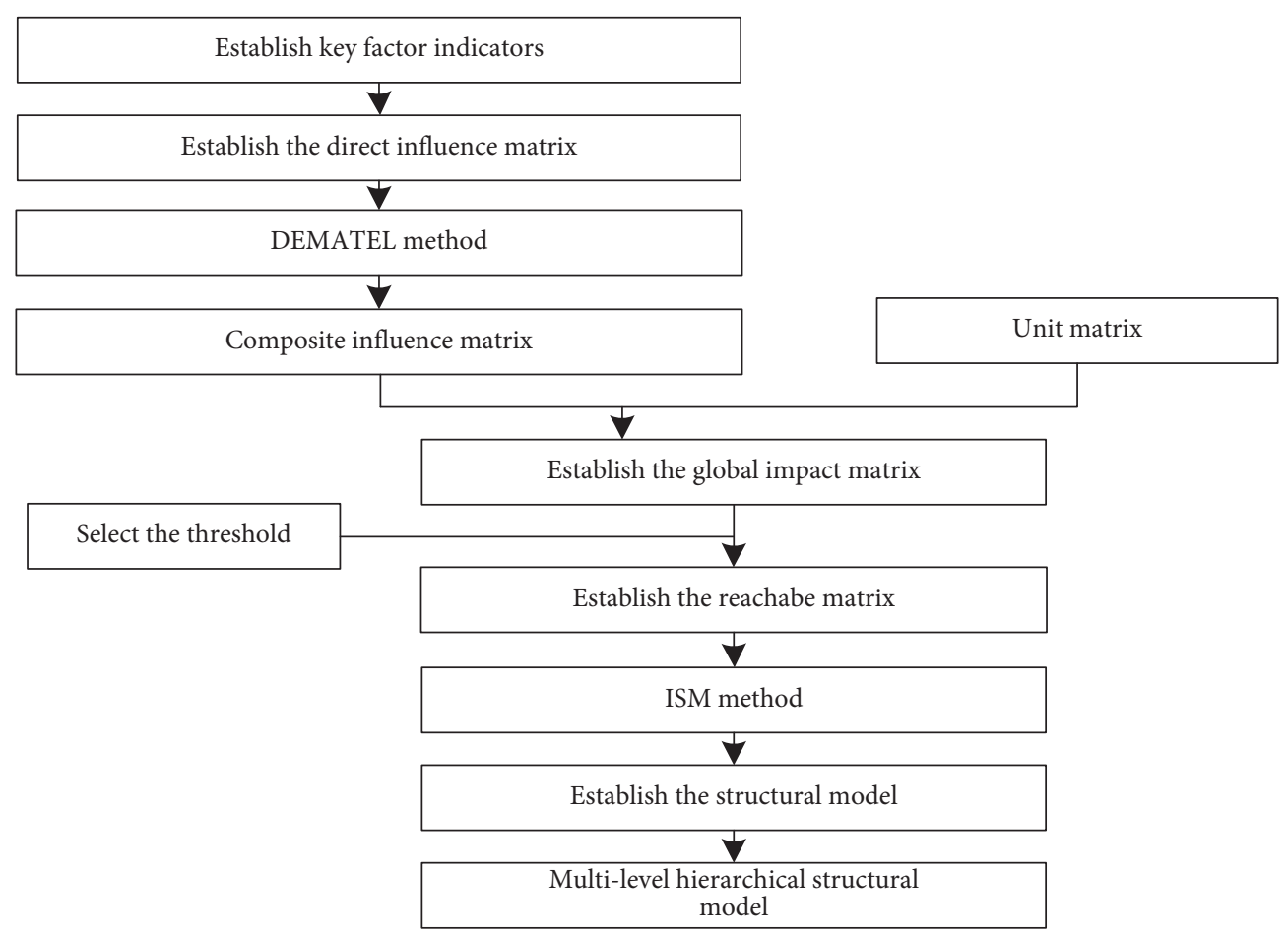

Figure 2: The integrated DEMATEL-ISM method.

Dominant important influencing factors directly affect matrix $W_{d d}$ :

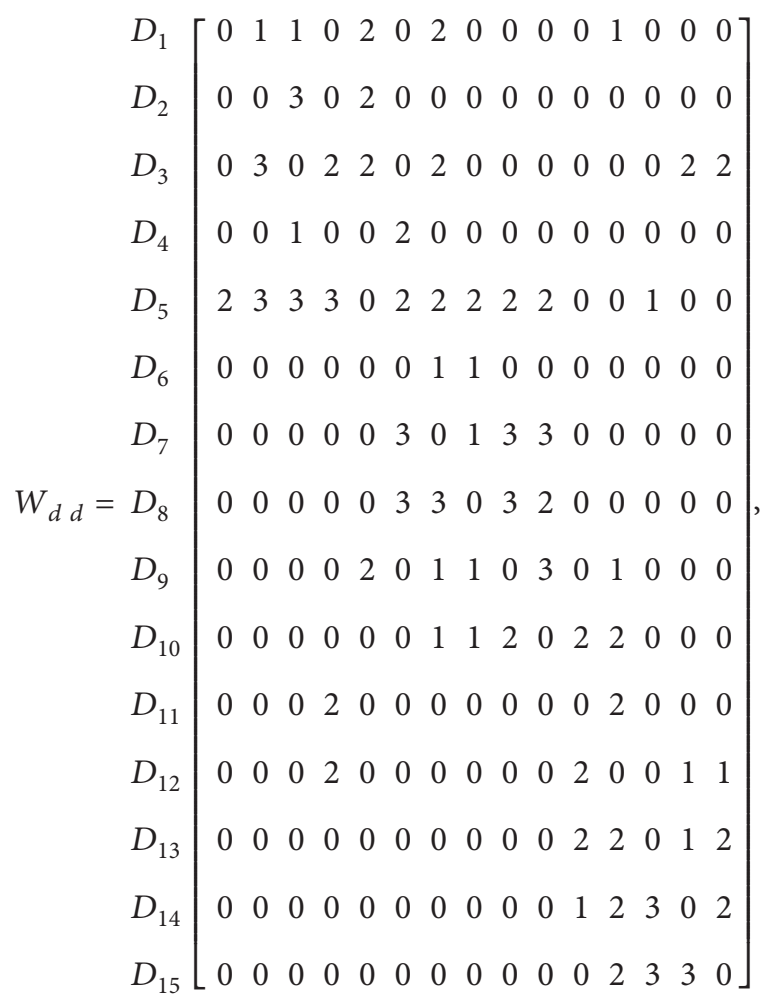

where 0 is no correlation between $D_{i}$ and $D_{j} ; 1$ is weak correlation between $D_{i}$ and $D_{j} ; 2$ is moderately correlated between $D_{i}$ and $D_{j} ; 3$ is the strong correlation between $D_{i}$ and $D_{j}$.
(2) Composite Influence Matrix. First, the direct influence matrix $W_{d}$ is normalized.

$$
W=\frac{1}{\max _{1 \leq i \leq n} \sum_{j=1}^{n} a_{i j}} W_{d} .
$$

The comprehensive influence matrix $K$ can be obtained by $\lim _{m \rightarrow \infty} W^{m}=0$.

$$
K=\lim _{m \longrightarrow \infty}\left(W+W^{2}+\cdots+W^{m}\right)=W(I-W)^{-1}=b_{i j},
$$

where $I$ is the identity matrix, that is, the influence of influencing factors on the self.

(3) Global Influence Matrix. By synthesizing the influence matrix $K$, the global influence matrix $L$ is calculated.

$$
L=K+I=p_{i j} .
$$

(4) Accessible Matrix. Let the Reachable Matrix be $H=$ $\left[h_{i j}\right]_{n \times n}, \quad i=1,2, \ldots, n ; j=1,2, \ldots, n$ and have the following relationship with the comprehensive influence matrix $K$ :

$$
h_{i j}=\left\{\begin{array}{l}
1, p_{i j} \geq \lambda \\
0, p_{i j} \leq \lambda
\end{array}\right.
$$

where $\lambda$ is the given threshold value. In this study, $\lambda=0.05$, the Reachable Matrix $H$ can be obtained by formula (3)-(6).

Reachable matrix of dominant important influencing factors $H$ : 


$$
\begin{aligned}
& D_{1}\left[\begin{array}{lllllllllllllll}
1 & 1 & 1 & 0 & 1 & 0 & 1 & 0 & 0 & 0 & 0 & 1 & 0 & 0 & 0 \\
0 & 1 & 1 & 0 & 1 & 0 & 0 & 0 & 0 & 0 & 0 & 0 & 0 & 0
\end{array}\right] \\
& D_{2} \quad \begin{array}{llllllllllllllll}
0 & 1 & 1 & 0 & 1 & 0 & 0 & 0 & 0 & 0 & 0 & 0 & 0 & 0 & 0
\end{array} \\
& \begin{array}{lllllllllllllllll}
D_{3} & 0 & 1 & 1 & 1 & 1 & 0 & 1 & 0 & 0 & 0 & 0 & 0 & 0 & 1 & 1
\end{array} \\
& D_{4} \quad \begin{array}{llllllllllllllll}
0 & 0 & 0 & 1 & 0 & 1 & 0 & 0 & 0 & 0 & 0 & 0 & 0 & 0 & 0
\end{array} \\
& D_{5} \quad \begin{array}{llllllllllllllll}
1 & 1 & 1 & 1 & 1 & 1 & 1 & 1 & 1 & 1 & 0 & 0 & 1 & 0 & 0
\end{array} \\
& D_{6} \quad \begin{array}{llllllllllllllll} 
& 0 & 0 & 0 & 0 & 1 & 1 & 1 & 0 & 0 & 0 & 0 & 0 & 0 & 0
\end{array} \\
& D_{7} \quad \begin{array}{llllllllllllllll}
0 & 0 & 0 & 0 & 0 & 1 & 1 & 1 & 1 & 1 & 0 & 0 & 0 & 0 & 0
\end{array} \\
& H=D_{8} \quad \begin{array}{llllllllllllllll}
0 & 0 & 0 & 0 & 0 & 1 & 1 & 1 & 1 & 1 & 0 & 0 & 0 & 0 & 0
\end{array} \\
& D_{9} \quad \begin{array}{llllllllllllllll}
0 & 0 & 0 & 0 & 1 & 0 & 1 & 1 & 1 & 1 & 0 & 1 & 0 & 0 & 0
\end{array} \\
& D_{10} \quad \begin{array}{llllllllllllllll}
0 & 0 & 0 & 0 & 0 & 0 & 1 & 1 & 1 & 1 & 1 & 1 & 0 & 0 & 0
\end{array} \\
& D_{11} \quad \begin{array}{llllllllllllllll} 
& 0 & 0 & 1 & 0 & 0 & 0 & 0 & 0 & 0 & 1 & 1 & 0 & 0 & 0
\end{array} \\
& D_{12} \quad \begin{array}{llllllllllllllll}
0 & 0 & 0 & 1 & 0 & 0 & 0 & 0 & 0 & 0 & 1 & 1 & 0 & 1 & 1
\end{array} \\
& D_{13} \quad \begin{array}{lllllllllllllll} 
& 0 & 0 & 0 & 0 & 0 & 0 & 0 & 0 & 0 & 1 & 1 & 1 & 1 & 1
\end{array} \\
& D_{14}\left[\begin{array}{lllllllllllllll}
0 & 0 & 0 & 0 & 0 & 0 & 0 & 0 & 0 & 0 & 1 & 1 & 1 & 1 & 1
\end{array}\right. \\
& D_{15}\left[\begin{array}{lllllllllllllll}
0 & 0 & 0 & 0 & 0 & 0 & 0 & 0 & 0 & 0 & 0 & 1 & 1 & 1 & 1
\end{array}\right]
\end{aligned}
$$

The dominant key influencing factors were divided into different levels, and their relationship was further judged by dividing each factor into different levels. Establish the Reachable Set $H\left(S_{i}\right)$, Antecedent Set $A\left(S_{j}\right)$, and Common Set $C$, which satisfy, respectively:

$H\left(S_{i}\right)$ : The set of factors corresponding to the columns whose elements are 1 in row $i$ of the Reachable Matrix;

$A\left(S_{j}\right)$ : The set of factors corresponding to the rows whose elements are 1 in column $j$ of the Reachable Matrix.

$$
C=H\left(S_{i}\right) \cap A\left(S_{j}\right) .
$$

When the elements in the set satisfy the conditions, the first level Reachable Set and Antecedent Set are obtained, as shown in Table 2. If $S_{i}$ satisfies $C=H\left(S_{i}\right) \cap A\left(S_{j}\right)$, then $S_{i}$ is the first level node of hierarchical division, which is marked in bold in the table, and the first level node is $L_{1}=(2,3,5,6,7,8,9,10,12,13,14,15)$.

Cross out row 2, 3, 5, 6, 7, 8, 9, 10,12, 13, 14, and 15 and column $2,3,5,6,7,8,9,10,12,13,14$, and 15 in the reachable matrix $\mathrm{H}$ to obtain a new reduced matrix $H_{1}$. Find secondlevel nodes, second-level Reachable Set and Antecedent Set according to the above method, as shown in Table 3 and obtain $L_{2}=(1,4)$.

Cross out row 1 and 4 and column 1 and 4 in the reduced matrix to get the new reduced matrix $\mathrm{H}_{2}$. Find the thirdlevel nodes, the third-level Reachable Set and Antecedent Set according to the above method, as shown in Table 4, and get $L_{3}=(11)$.

According to the Antecedent Set of the obtained threelevel Reachable Set, the hierarchy table of dominant important influencing factors for the realization of technological independent innovation of equipment manufacturing enterprises can be obtained, as shown in Table 5.
4.2.2. Hidden Influencing Factor. As above, the recessive important influencing factors directly affect the matrix $W_{d d}$ :

$$
\begin{aligned}
& \begin{array}{l}
R_{1} \\
R_{2}
\end{array}\left[\begin{array}{llllllllllll}
0 & 2 & 1 & 0 & 0 & 0 & 0 & 0 & 0 & 0 & 2 & 0 \\
3 & 0 & 2 & 0 & 0 & 0 & 0 & 0 & 0 & 0 & 1 & 0
\end{array}\right] \\
& R_{3} \quad \begin{array}{llllllllllll}
3 & 0 & 0 & 0 & 0 & 0 & 0 & 0 & 0 & 0 & 2 & 0
\end{array} \\
& R_{4} \quad \begin{array}{lllllllllllll}
0 & 0 & 0 & 1 & 0 & 0 & 0 & 0 & 0 & 0 & 0 & 0
\end{array} \\
& R_{5} \quad \begin{array}{lllllllllllll}
2 & 2 & 2 & 0 & 0 & 2 & 0 & 0 & 0 & 0 & 2 & 0
\end{array}
\end{aligned}
$$

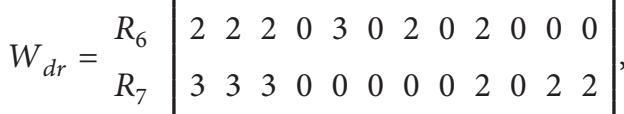

$$
\begin{aligned}
& R_{8} \quad \begin{array}{lllllllllllll}
0 & 0 & 0 & 0 & 0 & 0 & 0 & 1 & 0 & 0 & 0 & 1
\end{array} \\
& \begin{array}{l|llllllllllll}
R_{9} & 3 & 2 & 3 & 0 & 2 & 0 & 0 & 0 & 0 & 0 & 2 & 3
\end{array} \\
& R_{10} \quad \begin{array}{lllllllllllll}
0 & 0 & 0 & 0 & 3 & 3 & 0 & 0 & 2 & 0 & 2 & 2
\end{array} \\
& R_{11} \mid \begin{array}{llllllllllll}
3 & 2 & 2 & 0 & 0 & 1 & 0 & 0 & 0 & 3 & 0 & 1
\end{array} \\
& R_{12}\left[\begin{array}{llllllllllll}
3 & 3 & 3 & 0 & 2 & 2 & 3 & 0 & 3 & 3 & 3 & 0
\end{array}\right. \text {. }
\end{aligned}
$$

where 0 is no correlation between $R_{i}$ and $R_{j} ; 1$ is weak correlation between $R_{i}$ and $R_{j} ; 2$ is moderately correlated between $R_{i}$ and $R_{j} ; 3$ is the strong correlation between $R_{i}$ and $R_{j}$.

According to the formula, the Reachable Matrix $H$ of implicit important influencing factors can be obtained:

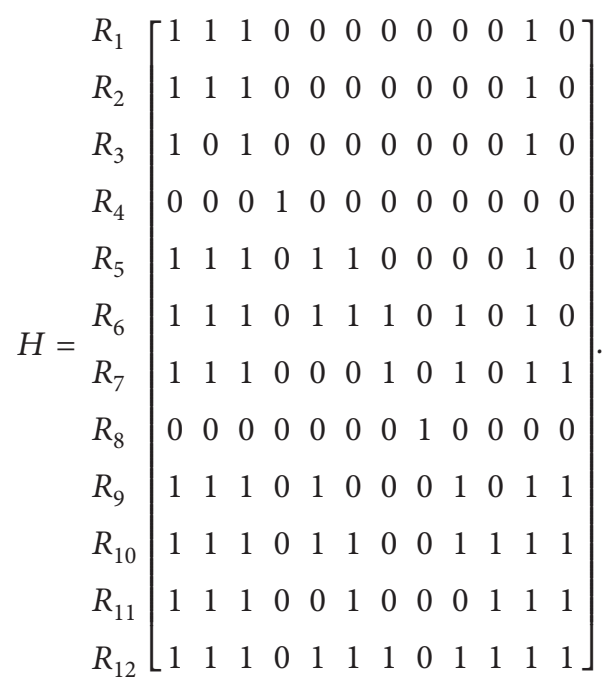

Through the Antecedent Set of the four-level reachable set obtained by calculation, the hierarchy table of the dominant important influencing factors for the technology independent innovation of equipment manufacturing enterprises can be obtained, as shown in Table 6 .

\subsection{Determination of Key Influencing Factors}

4.3.1. Dominant Key Influencing Factors. The first two levels in the hierarchy chart and $y_{i} \geq 0.7$ are recorded as the dominant key influencing factors. According to the importance evaluation value, the order is as follows: the degree of cooperation between $D_{7}$ and universities and scientific research institutes, the proportion of $D_{8}$ professional R \& D personnel, the construction of $D_{2}$ corporate culture, the 
TABLE 2: First reachable set and antecedent set in reachable matrix $H$.

\begin{tabular}{|c|c|c|c|}
\hline$S_{i}$ & $H\left(S_{i}\right)$ & $A\left(S_{j}\right)$ & $C=H\left(S_{i}\right) \cap A\left(S_{j}\right)$ \\
\hline 1 & $1,2,3,5,7,12$ & 1,5 & 1,5 \\
\hline 2 & $2,3,5$ & $1,2,3,5$ & $2,3,5$ \\
\hline 3 & $2,3,4,5,7,14,15$ & $1,2,3,5$ & $2,3,5$ \\
\hline 4 & 4,6 & $3,4,5,11,12$ & 4 \\
\hline 5 & $1,2,3,4,5,6,7,8,9,10,13$ & $1,2,3,5,9$ & $1,2,3,5,9$ \\
\hline 6 & $6,7,8$ & $4,5,6,7,8$ & $6,7,8$ \\
\hline 7 & $6,7,8,9,10$ & $1,3,5,6,7,8,9,10$ & $6,7,8,9,10$ \\
\hline 8 & $6,7,8,9,10$ & $5,6,7,8,9,10$ & $6,7,8,9,10$ \\
\hline 9 & $5,7,8,9,10,12$ & $5,7,8,9,10$ & $5,7,8,9,10$ \\
\hline 10 & $7,8,9,10,11,12$ & $5,7,8,9,10$ & $7,8,9,10$ \\
\hline 11 & $4,11,12$ & $10,11,12,13,14$ & 11,12 \\
\hline 12 & $4,11,12,14,15$ & $1,9,10,11,12,13,14,15$ & $11,12,14,15$ \\
\hline 13 & $11,12,13,14,15$ & $5,13,14,15$ & $13,14,15$ \\
\hline 14 & $11,12,13,14,15$ & $3,12,13,14,15$ & $12,13,14,15$ \\
\hline 15 & $12,13,14,15$ & $3,12,13,14,15$ & $12,13,14,15$ \\
\hline
\end{tabular}

Table 3: The second-level Reachable Set and Antecedent Set in the reduced matrix $H_{1}$.

\begin{tabular}{lccc}
\hline$S_{i}$ & $H\left(S_{i}\right)$ & $A\left(S_{j}\right)$ & $C=H\left(S_{i}\right) \cap A\left(S_{j}\right)$ \\
\hline 1 & $\mathbf{1}$ & 1 & $\mathbf{1}$ \\
4 & $\mathbf{4}$ & 4,11 & $\mathbf{4}$ \\
11 & 4,11 & 11 & 11
\end{tabular}

TABle 4: The third Reachable Set and Antecedent Set in reduced matrix $\mathrm{H}_{2}$.

\begin{tabular}{cccc}
\hline$S_{i}$ & $H\left(S_{i}\right)$ & $A\left(S_{j}\right)$ & $C=H\left(S_{i}\right) \cap A\left(S_{j}\right)$ \\
\hline 11 & $\mathbf{1 1}$ & 11 & $\mathbf{1 1}$ \\
\hline
\end{tabular}

sensitivity and risk awareness of $D_{5}$ entrepreneurs' independent technological innovation, $D_{14}$ users' satisfaction with products, the production rate of $D_{6}$ research results, and $D_{10}$ product technology innovation level.

4.3.2. Hidden Key Influencing Factors. The first two levels in the hierarchical structure chart and $y_{i} \geq 0.7$ are recorded as hidden key influencing factors. According to the importance evaluation value, the order is as follows: $R_{3}$ introduction of advanced technological achievements, $R_{11}$ scale of industry university research cooperation platform, the degree of promoting enterprise technology independent innovation in the region where $R_{12}$ enterprise is located, $R_{1}$ technology $\mathrm{R} \& \mathrm{D}$ investment level, $R_{2} \mathrm{R} \& \mathrm{D}$ investment growth rate, and $R_{6}$ market demand.

To sum up, according to the empirical analysis results, the secondary dominant influencing factors include the construction of corporate culture, the sensitivity, and risk awareness of entrepreneurs' technological independent innovation. Innovation capability includes the production rate of research results, the degree of cooperation with universities and scientific research institutes, and the proportion of professional R\&D personnel. Innovative products include product technology innovation level. Innovation participation includes users' satisfaction with products, with special attention to innovation strength and innovation ability. The second-level hidden influencing factors of innovation investment include the level of technology R\&D investment, the growth rate of R\&D investment, and the introduction of advanced technological achievements. The innovation environment includes the market demand, the scale of industry university research cooperation platform, the degree of promoting independent technological innovation in the region where the enterprise is located, and the government and universities (scientific research institutions) because the main body of innovation should pay attention to these two aspects at the same time.

\section{Countermeasures to Realize the Technology Independent Innovation of Equipment Manufacturing Enterprises}

Based on the iceberg theory, this study analyzes the explicit and implicit influencing factors of the technology independent innovation of equipment manufacturing enterprises. According to the main role of the explicit and implicit influencing factors, a strategic model for the realization of the technology independent innovation of equipment manufacturing enterprises is constructed (as shown in Figure 3), and specific countermeasures and suggestions are put forward.

\subsection{The Leading Role of the Government}

5.1.1. Increase Investment in Innovation and Building a Combined Chain of Supporting Policies. The government should increase the investment in innovation, effectively integrate and allocate relevant resources, give key support to key enterprises and key products technologies, build a comprehensive and continuous supporting policy combination chain, draw the planning map of supporting policy combination chain, and comprehensively guarantee the realization of independent technology innovation of equipment manufacturing enterprises. According to the actual feedback, we will adjust policy planning, timely 
TABLE 5: Hierarchy of explicit important influencing factors for the realization of technological independent innovation in equipment manufacturing enterprises.

\begin{tabular}{lc}
\hline Level & Influencing factors \\
\hline & $D_{2}$ corporate culture construction status, $D_{3}$ enterprise management team quality, $D_{5}$ the acuity and risk consciousness of \\
entrepreneur's technology independent innovation, $D_{6}$ production rate of research results, $D_{7}$ degree of cooperation with \\
I & universities and research institutes, $D_{8}$ proportion of professional R\&D personnel, $D_{9}$ success rate of technological innovation, $D_{10}$ \\
& product technology innovation level, $D_{12}$ product market share, $D_{13}$ the degree to which users want the product, $D_{14}$ customer \\
& satisfaction with the product, $D_{15}$ how much trust users have in the product \\
II & $D_{1}$ enterprise size, $D_{4}$ enterprise financial status in 5 years \\
III & $D_{11}$ product production rate \\
\hline
\end{tabular}

TABLE 6: Hierarchy of hidden important influencing factors for the realization of technology independent innovation in equipment manufacturing enterprises.

\begin{tabular}{lc}
\hline Level & Influencing factors \\
\hline & $R_{1}$ technology R\&D investment level, $R_{2}$ growth rate of R\&D investment, $R_{3}$ the introduction of advanced technological \\
I & achievements, $R_{4}$ market structure, $R_{6}$ market demand, $R_{8}$ scale of infrastructure construction, $R_{10}$ customer satisfaction with \\
& product acquisition, $R_{11}$ scale of industry-university-research cooperation platform, $R_{12}$ the degree to which the enterprise is located \\
& promotes its independent technological innovation \\
II & $R_{5}$ scale of market competition \\
III & $R_{9}$ intensity of financial support for technology development \\
IV & $R_{7}$ intensity of government technical subsidies \\
\hline
\end{tabular}

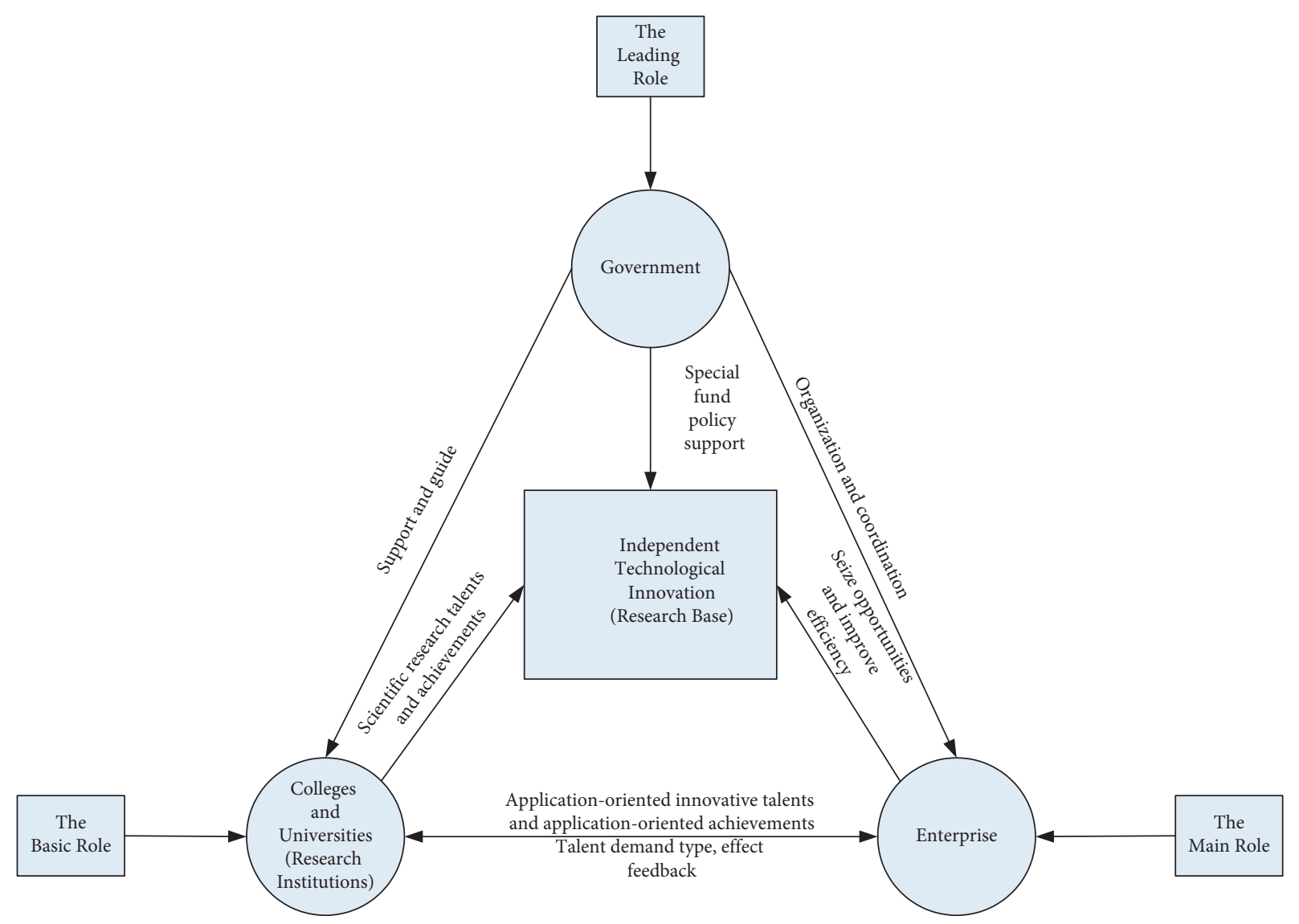

FIGURE 3: Strategy model of technology independent innovation of equipment manufacturing enterprises. 
complement the chain, strengthen the chain, and extend the chain to ensure the sustainability of the combination chain of government support policy synergy.

\subsubsection{Create an Innovative Ecological Environment: The Ex-} ogenous Stimulation Cycle Leads to the Endogenous Dynamic Cycle. The government needs to create an innovation ecological environment for the equipment manufacturing enterprises' independent technological innovation and stimulate and induce the power cycle of the equipment manufacturing enterprises' internal independent innovation through the government's external policy of optimizing the innovation environment. At the same time, we will stimulate and supervise external forces, improve the environment for innovation, gather superior resources, promote the deep integration of industry-university-research and application, accelerate the high-quality transformation of scientific and technological achievements, and strengthen the capacity of original independent innovation, integrated independent innovation, introduction and absorption of core technologies, and then independent innovation.

\subsection{The Basic Role of Universities (Research Institutions)}

5.2.1. Strengthen the Cultivation of Professional Talents to Comprehensive Talents and Promote the High-Quality Transformation of Scientific and Technological Achievements. Colleges and universities (research institutions) should meet the demand of manufacturing enterprises and market, new talent training mode, timely adjustment of professional curriculum and content, and strengthen the training of professional talents to comprehensive talents [44]. Aiming at the forefront of science and technology in the equipment manufacturing industry and its future industrial development, it is conducive to the commercialization of research results, promote the high-quality transformation of scientific and technological achievements, and truly integrate production with learning.

5.2.2. Strengthen Effective Cooperation and Communication and Establish a Strategic Alliance between Industry-UniversityResearch Institutes with Complementary Advantages and High-Quality Development. Actively build cooperation and exchange platforms, improve the efficiency of cooperation and communication between universities (research institutions) and equipment manufacturing enterprises, and actively promote the establishment of industry-universityresearch strategic alliance. Ensure the complementarity of heterogeneous resources of both sides, conquer key core technologies, and achieve win-win results.

\subsection{The Main Role of Enterprises}

5.3.1. Form a Diversified Investment System and Improve Our Capacity for Independent Technological Innovation. In terms of cultural construction, managers should play a leading role, actively participate in innovative cultural construction activities, stimulate the enthusiasm of employees for independent innovation, make employees establish the concept of technological independent innovation, and improve their enthusiasm for technological independent innovation. In terms of capital investment, in addition to government funding, the more important thing for enterprises is to look for potential investors by themselves, introduce foreign capital and social investment, and improve the investment intensity of technological innovation capital.

\subsubsection{Establish a Sound Technology Innovation Platform and} Enhance Technology Learning and Absorption Capacity. Utilizing the advanced technology means of Internet and information technology, the technology big data center of national equipment manufacturing enterprises has been set up, covering the information of advanced technology data and enterprises' technological innovation needs, so as to realize more efficient resource sharing and optimal utilization, and provide good support for learning and absorbing technology. The research and development team led by backbone innovation talents, on the basis of the introduction of advanced technology, realize reinnovation, gradually complete the goal of independent design and production, improve technology learning and absorption capacity, solve the problem of independent technology innovation, and break the bottleneck of development.

5.3.3. Cultivate and Introduce Overseas Talents and Optimize the Talent Structure. Equipment manufacturing enterprises need to formulate systematic plans for training and introducing talents, fully expand talent training channels, absorb overseas excellent talents, further improve the talent incentive mechanism, link the salary and treatment of all kinds of talents with their abilities, change the single material incentive mode, and attach importance to the spiritual incentive.

\section{Conclusion}

The improvement of the technology independent innovation ability of equipment manufacturing enterprises can effectively drive the development of related industries, which is conducive to the sustainable development of equipment manufacturing enterprises and the rapid development of the overall economy. In this study, according to the current situation of the development of equipment manufacturing industry enterprise technology innovation, based on the iceberg theory analysis of the equipment manufacturing industry enterprise technology innovation of explicit and implicit factors influencing factors, further integration DEMATEL-ISM method are used to obtain 7 explicit influencing factors, including the construction of corporate culture, and 6 implicit influencing factors, including the level of technology $\mathrm{R} \& \mathrm{D}$ investment, in order to realize the equipment manufacturing industry enterprise technical innovation countermeasures, and suggestions are put forward. Different from previous studies, this study selects a combination of methods to determine the alternative 
influencing factors of technological independent innovation of equipment manufacturing enterprises from the literature. Then, the dominant and recessive important influencing factors are selected by Delphi expert investigation method. Finally, the hierarchical structure between explicit and implicit important influencing factors is analyzed by using the integrated DEMATEL-ISM method, and the explicit and implicit key factors of technological independent innovation of equipment manufacturing enterprises are obtained, which enriches and expands the exploration and application of such problems, and provides a new direction for equipment manufacturing enterprises to improve the ability of technological independent innovation and high-quality development.

From the perspective of iceberg theory, this study provides basic research ideas for the research of technology independent innovation of equipment manufacturing enterprises and also provides guidance for the division of influencing factors of technology independent innovation of equipment manufacturing enterprises. However, due to the limitations of its own level and research conditions, the research on this aspect will continue to be deepened in the future, especially focusing on and breaking through the selection of evaluation indexes for influencing factors of technology independent innovation in equipment manufacturing enterprises. In this study, considering the convenience of calculation and the availability of data, the influencing factors of technology independent innovation of equipment manufacturing enterprises are used to determine the evaluation index, but the influencing factors of technology independent innovation of equipment manufacturing enterprises are a complex system. Therefore, in the future research, it is necessary to improve the selection of evaluation indicators of influencing factors of technological independent innovation of equipment manufacturing enterprises, which can be done using following steps. (1) emphasize the purpose, the purpose of the selected indicators is clear, and the selected indicators can really reflect the relevant contents. (2) Pay attention to comprehensiveness, and the selected indicators should cover the evaluation content as much as possible. If there is any omission, the evaluation will deviate. Another way to say that it is more comprehensive is that it is representative, and the selected indicators can really reflect the evaluation content. (3) The quantitative index screening method should pay attention to the independence and logical correlation between indicators, and the rationality and accuracy of the actual evaluation process also need to be further verified.

\section{Data Availability}

The data used to support the findings of this study are available from the corresponding author upon request.

\section{Conflicts of Interest}

All the authors declare that they have no conflicts of interest.

\section{Acknowledgments}

This research was funded by National Natural Science Found Project (71774035); Ministry of Education Humanities and
Social Sciences Research Planning Fund Project (19YJA630015); and Natural Science Fund of Heilongjiang Province (LH2019G005).

\section{References}

[1] M. Fransman and K. King, Technological Capability in the Third World, Macmillan, London, UK, 1984.

[2] G. Raghu and R. Praveen, "Transformative capacity: continual structuring by intertemporal technology transfer," Strategic Management Journal, vol. 15, no. 3, pp. 365-395, 1994.

[3] W. W. Wu, B. Yu, and C. Wu, "How China's equipment manufacturing firms achieve successful independent innovation," Chinese Management Studies, vol. 6, no. 1, pp. 160-183, 2012.

[4] Y. Q. Wang, Q. Y. Jin, Y. F. Gong, and M. M. Sun, "The improvement of independent innovation capability in petroleum equipment manufacturing industry based on knowledge integration," Advanced Materials Research, vol. 869, pp. 1080-1084, 2014.

[5] Z.-J. Zhou, P.-Y. Zhang, M.-M. Lu, and Z. Gao, "The influence of government intervention on the performance of independent innovation under financial support based on data of listed companies in strategic emerging industries," Mathematical Problems in Engineering, vol. 2020, Article ID 5063986, 9 pages, 2020.

[6] V. De Marchi, "Environmental innovation and R\&D cooperation: empirical evidence from Spanish manufacturing firms," Research Policy, vol. 41, no. 3, pp. 614-623, 2012.

[7] Á. Triguero and D. Córcoles, "Understanding innovation: an analysis of persistence for Spanish manufacturing firms," Research Policy, vol. 42, no. 2, pp. 340-352, 2013.

[8] M. Vokoun, "Innovation behaviour of firms in a small open economy: the case of the Czech manufacturing industry," Empirica, vol. 43, no. 1, pp. 111-139, 2016.

[9] Y. Zhu and H.-y. Lei, "Fuzzy AHP analysis on enterprises' independent innovation capability evaluation," Physics Procedia, vol. 24, pp. 1285-1291, 2012.

[10] J. L. Hervasoliver, F. Sempereripoll, R. R. Alvarado, and E. M. Sofia, "Beyond product innovation: deciphering process-oriented innovators, complementarities and performance effects," Technology Analysis \& Strategic Management, vol. 7, pp. 1-14, 2017.

[11] H. T. Zhang, W. D. Zhu, D. P. Wang, and G. Z. Zhou, "Independent innovation capability evaluation for automobile industry of Anhui province based on evidential reasoning," in Proceedings of the IEEE 2009 International Conference on Management Science and Engineering, pp. 1854-1859, Vancouver, Canada, August 2009.

[12] L. B. Si and H. Y. Qiao, "Evaluation of technological innovation efficiency in equipment manufacturing industry based on input orientation-Panel data analysis based on data envelopment mode," Journal of Discrete Mathematical Sciences and Cryptography, vol. 20, no. 6-7, pp. 1381-1386, 2017.

[13] Y. Lin, N. Deng, and H. Gao, "Research on technological innovation efficiency of tourist equipment manufacturing enterprises," Sustainability, vol. 10, no. 12, pp. 1-17, 2018.

[14] S. A. Feldman, The Iceberg Theory-Fact or Fiction? Implication for Monitoring, pp. 257-261, Springer, Tokyo, Japan, 1995.

[15] M. Chamon and E. Kaplan, "The iceberg theory of campaign contributions: political threats and interest group behavior," American Economic Journal: Economic Policy, vol. 5, no. 1, pp. 1-31, 2013. 
[16] S. Y. Wang, J. N. Ao, Q. Han, Y. F. Yang, Y. Hu, and M. Jiang, "Iceberg Theory: a new methodology for studying business model from knowledge management perspective," Management Review, vol. 27, no. 6, pp. 3-10, 2015.

[17] T. Hines, "Developing an Iceberg Theory of cost comparisons in relation to sourcing decisions by UK fashion retailers," Journal of the Textile Institute, vol. 93, no. 3, pp. 3-14, 2002.

[18] Y. Guan and L. Liang, "The profitability model of high-tech enterprise based on the Iceberg Theoretical approach-a case study of Zhejiang," Soft Science, vol. 24, no. 5, pp. 78-82, 2010.

[19] K. Abbasi, "The iceberg theory of NHS culture," $S A G E$, vol. 104, no. 2, p. 47, 2011.

[20] P. Gui and S. Na, "Empirical study on the application of activity-based cost model in marine third-party logistics cost management," Journal of Coastal Research, vol. 98, pp. 195-198, 2019.

[21] N. P. Grigg, J. E. Goodyer, and T. G. Frater, "Sustaining lean in SMEs: key findings from a 10-year study involving New Zealand manufacturers," Total Quality Management and Business Excellence, vol. 31, no. 5-6, pp. 609-622, 2020.

[22] M. Chen, C. Zhang, D. Liu, and Q. Mao, "Study on talents ability and quality of building environment and energy engineering major based on iceberg theory," in Proceedings of the 6th International Conference On Education Reform And Modern Management (ERMM 2021), pp. 243-246, Atlantis Press, Beijing, China, April 2021.

[23] L. Cao and G. Dong, "Human resource management model innovation of forestry science and technology enterprises in the era of big data," Forest Chemicals Review, pp. 95-106, 2021.

[24] P. Ru, Q. Zhi, F. Zhang, X. Zhong, J. Li, and J. Su, "Behind the development of technology: the transition of innovation modes in China's wind turbine manufacturing industry," Energy Policy, vol. 43, pp. 58-69, 2012.

[25] G. Di Stefano, A. Gambardella, and G. Verona, "Technology push and demand pull perspectives in innovation studies: current findings and future research directions," Research Policy, vol. 41, no. 8, pp. 1283-1295, 2012.

[26] Z. Yu and H. Y. Lei, "Fuzzy AHP analysis on enterprises' independent innovation capability evaluation," Physics Procedia, vol. 24, pp. 1285-1291, 2012.

[27] Y. Q. Wang, Q. Y. Jin, Y. F. Gong, and M. M. Sun, "The improvement of independent innovation capability in petroleum equipment manufacturing industry based on knowledge integration," Advanced Materials Research, vol. 869, pp. 1080-1084, 2013.

[28] P. Soto-Acosta, S. Popa, and I. Martinez-Conesa, "Information technology, knowledge management and environmental dynamism as drivers of innovation ambidexterity: a study in SMEs," Journal of Knowledge Management, vol. 22, no. 4, pp. 931-948, 2018.

[29] L. Lin and F. L. Wang, "Geographical proximity vs. network tie: innovation of equipment manufacturing firms in Shanghai, China," Erdkunde, vol. 37, no. 3, pp. 185-198, 2019.

[30] J. G. Gao, E. J. Xia, and S. Wei, "A study on chinese listed companies based on evaluation of independent innovation capability," in Proceedings of the 2009 International Conference On Information Management, Innovation Management And Industrial Engineering, pp. 1804-1809, IEEE, Xian, China, December 2009.

[31] H. Zhao and C. Zhu, "Evaluation model of technological learning efficiency based on independent innovation," IEEE in Proceedings of the 2009 international Conference on information management, innovation Management and industrial engineering, vol. 4, pp. 611-614, Xian, China, December 2009.

[32] G. H. He, L. T. Liu, and X. X. Chang, "A study on the relationship between financial structure and firm independent innovation in China," Economic Management Journal, vol. 3, pp. 1-7, 2011.

[33] H. Berglund and T. Hellstrom, "Enacting risk in independent technological innovation," International Journal of Risk Assessment and Management, vol. 3, no. 4, pp. 205-221, 2002.

[34] T. Hellström and C. Hellström, "Time and innovation in independent technological ventures," Human Relations, vol. 55, no. 4, pp. 407-426, 2002.

[35] R. M. Knight, "Technological innovation in Canada: a comparison of independent entrepreneurs and corporate innovators," Journal of Business Venturing, vol. 4, no. 4, pp. 281-288, 1989.

[36] D. Z. Du, "Network oligopolistic market structure and enterprise's technological innovation-the market structure conditions for Chinese enterprise's independent technical innovation," China Industrial Economy, vol. 11, pp. 14-21, 2006.

[37] W. Zhang, Y. Jiang, and W. Zhang, “Antecedents of online knowledge seeking of employees in technical R\&D team: an empirical study in China," IEEE Transactions on Engineering Management, vol. 99, pp. 1-10, 2021.

[38] X. H. Xu, "Problems and solutions of the scientific and technological innovation supporting the independent innovation of enterprises," Scientific Management Research, vol. 29, no. 4, pp. 109-112, 2011.

[39] W. Zhang, S. L. Sun, Y. Jiang, and W. Zhang, "Openness to experience and team creativity: effects of knowledge sharing and transformational leadership," Creativity Research Journal, vol. 31, no. 1, pp. 62-73, 2019.

[40] X. Yang, Y. Guo, Q. Liu, and D. Zhang, "Empirical evaluation on the effect of enterprise quality immune response based on EMIBSGTD-TAS," Journal of Intelligent and Fuzzy Systems, vol. 40, no. 6, pp. 11587-11606, 2021.

[41] K. Fu, J.-B. Xia, X.-Y. Zhang, and J. Shen, "System structural analysis of communication networks based on DEMATELISM and entropy," Journal of Central South University, vol. 24, no. 7, pp. 1594-1601, 2017.

[42] K. NaNa and M. Jiao, "Studies of public participation ability elements of food safety governance based on DEMATELISM," Journal of Food Safety and Quality, vol. 10, no. 3, pp. 811-817, 2019.

[43] A. Trivedi, S. K. Jakhar, and D. Sinha, "Analyzing barriers to inland waterways as a sustainable transportation mode in India: a DEMATEL-ISM based approach," Journal of Cleaner Production, vol. 295, pp. 126-301, 2021.

[44] W. Zhang, Y. Jiang, and W. Zhang, "Capabilities for collaborative innovation of technological alliance: a knowledgebased view," IEEE Transactions on Engineering Management, vol. 99, pp. 1-11, 2019. 